\title{
SYNTHESIS OF Scylla Serrata SHELL DERIVED CHITOSAN- COATED MESOPOROUSMAGNETIC NANO ADSORBENT FOR Cr(VI) REMOVAL FROM AQUEOUS SOLUTIONS
}

\author{
T. Ravi and Sathish Sundararaman ${ }^{凶}$ \\ Department of Chemical Engineering, Sathyabama Institute of Science and Technology, \\ Chennai-600119, Tamil Nadu, India. \\ Corresponding Author: sathish.chemical@sathyabama.ac.in
}

\begin{abstract}
Mesoporous magnetic chitosan nano-sorbents (m-MCNS) were synthesized by the co-precipitation reaction of Scylla serrata shell-derived chitosan and iron oxide nanoparticles using glutaraldehyde cross-linkers. The prepared m-MCNS were highly crystalline, porous, and spherical with an average size of $21.6 \mathrm{~nm}$ and surface area of 28.3 $\mathrm{m}^{2} / \mathrm{g}$ and exhibiting magnetic saturation of $9.1917 \mathrm{emu} / \mathrm{g}$. The synthesized m-MCNS was tested to determine its adsorptive capacity $\mathrm{Cr}$ (VI). An optimized removal of $98.7 \%$ was obtained with 0.3 gram of m-MCNS at $\mathrm{pH}$ of 5.5 at $303 \mathrm{~K}$ for an initial concentration $100 \mathrm{mg} / \mathrm{L}$ of $\mathrm{Cr}(\mathrm{VI})$. Langmuir isotherm fit experimental data better than other models. The adsorptive kinetics agreed well with the pseudo-second-order model. The m-MCNS adsorbent has greater potential to remove $\mathrm{Cr}(\mathrm{VI})$ from the wastewater.
\end{abstract}

Keywords: Nano-sorbents, Adsorption, Kinetics, Isotherm, Chitosan, Mesoporous

RASĀYAN J. Chem., Vol. 14, No.2, 2021

\section{INTRODUCTION}

The environment, human health, and aquatic life were seriously affected by the industrial exit which contains poisonous substantial metal toxins. Among all these, after Arsenic the Chromium is one of the important and essential heavy metals used in the various sectors which tends to severe threat when it is mixed with water sources and more toxic. $\mathrm{Cr}^{3+}$ and $\mathrm{Cr}^{6+}$ are the significant oxidation types of chromium that exists in wastewater releases. ${ }^{1}$ Among these, the $\mathrm{Cr}(\mathrm{VI})$ is considered as a harmful metal and makes cancer-causing and poisonous impacts people and displays amphibian life poisonous. ${ }^{2}$ Even though the wide assortment of $\mathrm{Cr}$ (VI) expulsion strategies, the adsorption is increasingly fit given its selectivity, ease, profoundly effectiveness, simple dealing with, re-usability, and suitability. ${ }^{3}$ In recent years, the synthesis of magnetic adsorbents was proved to be more prominent for the exclusion of $\mathrm{Cr}(\mathrm{VI})$ by simplifying the practice in recuperating the adsorbed material with an external magnet when compared to coagulation and precipitation. ${ }^{4}$ Chitosan is a natural biopolymer available in large quantities in the form of chitin and derived from the shells of shrimp, crab, prawn, and crawfish. ${ }^{5}$ The cross-linking of Chitosan remarkably improved in the previous research studies for targeted drug delivery, dye removal, heavy metal removal, and protein adsorption with the prolonged ability with higher crystallinity, hydrophilicity, degradation. ${ }^{6}$ In this exploration, the glutaraldehyde crosslinked chitosan which has been separated from Scylla serrata shell, deacetylated and was adequately covered on the magnetic iron oxide by ultrasonic bath tailored co-precipitation strategy. The physio-chemical, morphological, surface, porosity, functional bonds, and magnetic properties were characterized. A lot of sorption tests were conducted to analyse the optimal operating conditions.

\section{Materials and Methods}

\section{EXPERIMENTAL}

All the reagents and chemicals were procured from Sigma-Aldrich, Chennai, India. All the analytical reagents were made with the use of de-ionized water. ${ }^{7}$

\section{Extraction of Chitosan from Crab Shell}

The crab shells were collected from the local market in Chennai, India and washed to remove impurities. The dried shells were ground into a fine powder and stored at $4^{\circ} \mathrm{C}$. In the demineralization process, $2 \mathrm{M}$ of 
RASĀYAN J. Chem.

Vol. 14 | No. 2 |1105-1109| April - June | 2021

$\mathrm{HCl}$ was added to the powdered shell at $60^{\circ} \mathrm{C}$ and the mixture was agitated at $200 \mathrm{rpm}$ for $2 \mathrm{hr}^{8}{ }^{8} \mathrm{The}$ resultant shells were deproteinized by adding it with $3 \mathrm{M}$ of $\mathrm{NaOH}$ at $80^{\circ} \mathrm{C}$ with the agitation rate of 200 $\mathrm{rpm}$ for $2 \mathrm{~h}$. The organic compounds present in the mixture were treated with a solution that contains an $8: 2$ weight ratio of $0.1 \mathrm{M} \mathrm{H}_{2} \mathrm{O}_{2}$ and $10 \mathrm{M} \mathrm{HCl}$. The mixture was washed several times with acetone and dried for $2 \mathrm{hr}$ at $30^{\circ} \mathrm{C}$ to obtain chitin. The deacetylation of the chitin was carried out by treating it with $15 \mathrm{M}$ of $\mathrm{NaOH}$ at $110^{\circ} \mathrm{C}$ under vacuum with constant stirring for $5 \mathrm{~h}$ and filtered. ${ }^{9}$ The resultant chitosan was cooled and rinsed thoroughly with de-ionized water until the solution $\mathrm{pH}$ approached neutral. The chitosan was then allowed to dry overnight.

\section{Synthesis of m-MCNS Magnetic Nanoadsorbent}

The m-MCNS were prepared by co-precipitation reaction ${ }^{10}$ aided with ultrasonic bath. $\mathrm{FeCl}_{3}$ and $\mathrm{FeSO}_{4} .7 \mathrm{H}_{2} \mathrm{O}$ were taken with $2: 1$ by weight in $50 \mathrm{ml}$ of $\mathrm{H}_{2} \mathrm{O}$ at $40^{\circ} \mathrm{C}$ for $1 \mathrm{hr}$ at a $200 \mathrm{rpm}$ agitation rate. $0.35 \mathrm{~g}$ of extracted chitosan was added with $15 \mathrm{ml}$ of glutaraldehyde cross-linking agent and thoroughly stirred for $2 \mathrm{hr}$ at $200 \mathrm{rpm}$. The co-precipitation reaction was initiated by adding a $50 \mathrm{ml}$ drop-wise solution of $\mathrm{NH}_{4} \mathrm{OH}$ with the reaction mixture which abandoned reddish-brown colored into black. The slurry containing magnetic chitosan particles was several times washed with water and ethanol and dried in an oven at $60^{\circ} \mathrm{C}$. The m-MCNS were characterized by XRD, FT-IR, VSM, FESEM and BET.

\section{Adsorption Studies}

$1,000 \mathrm{mg} / \mathrm{L}$ of $\mathrm{Cr}$ (VI) was prepared by dissolving $2.857 \mathrm{~g}$ of $\mathrm{K}_{2} \mathrm{Cr}_{2} \mathrm{O}_{7}$ in $1000 \mathrm{~mL}$ of $\mathrm{H}_{2} \mathrm{O}$ and kept as a stock solution. ${ }^{11}$

$$
\% \text { Removal }=\frac{\left(C_{i}-C_{o}\right)}{C_{i}} \times 100
$$

Where, $C_{i}$ is the initial Cr (VI) concentration, $C_{o}$ and $C_{t}$ are the initial and final $\mathrm{Cr}$ (VI) concentration $(\mathrm{mg} / \mathrm{L})$ were analyzed by AAS spectrometer.

\section{Adsorption Isotherms}

The batch adsorption data were examined for the equilibrium characteristics.

$$
\begin{aligned}
Q_{e} & =\frac{Q_{m} K_{L} C_{e}}{1+K_{L} C_{e}} \\
Q_{e} & =K_{F} C_{e}^{1 / n} \\
Q_{e} & =B \ln \left(K_{T} C_{e}\right)
\end{aligned}
$$

Where, $\mathrm{Q}_{\mathrm{e}}$ and $\mathrm{Q}_{\mathrm{m}}$ are the equilibrium and highest monolayer adsorption capacity of $\mathrm{m}-\mathrm{MCNS}(\mathrm{mg} / \mathrm{g})$, $\mathrm{K}_{\mathrm{L}}, \mathrm{K}_{\mathrm{F}}, \mathrm{K}_{\mathrm{T}}$ is the Langmuir, Freundlich and Temkin constant respectively.

\section{Chemical Kinetics}

The separation time can be computed through kinetics studies using the following equations: ${ }^{12}$

$$
\begin{array}{r}
\log \left(Q_{e}-Q_{t}\right)=\log Q_{e}-0.4342 k_{1} t \\
\frac{t}{Q_{t}}=\frac{1}{k_{2} Q_{e}^{2}}+\frac{t}{Q_{e}}
\end{array}
$$

Where $\mathrm{Q}_{\mathrm{t}}$ is the adsorption capacity of m-MCNS at time $\mathrm{t}(\mathrm{mg} / \mathrm{g})$, and $k_{1}$ and $k_{2}$ are kinetic constants.

\section{Characterization of Adsorbent}

\section{RESULTS AND DISCUSSION}

The XRD pattern of m-MCNS (Fig.-1a) showed the characteristic peaks of $30.36^{\circ}, 35.72^{\circ}, 43.48^{\circ}$, $53.83^{\circ}, 57.39^{\circ}$, and $62.12^{\circ}$ corresponding to planes corresponding to the existence of the $\mathrm{Fe}_{3} \mathrm{O}_{4}$ nanoparticles. It also shows the absence of the peak at $33.15^{\circ}$ for $\mathrm{FeO}(\mathrm{OH})$ and $21.22^{\circ}$ for $\mathrm{Fe}_{2} \mathrm{O}_{3}$ confirmed that the prepared m-MCNS were free from iron-containing impurities. Fig.-1b illustrates the 
RASĀYAN J. Chem.

Vol. 14 | No. 2 |1105-1109| April - June | 2021

SEM micrograph image of m-MCNS which proves the spherically shaped nanoparticles with ample void spaces were observed.
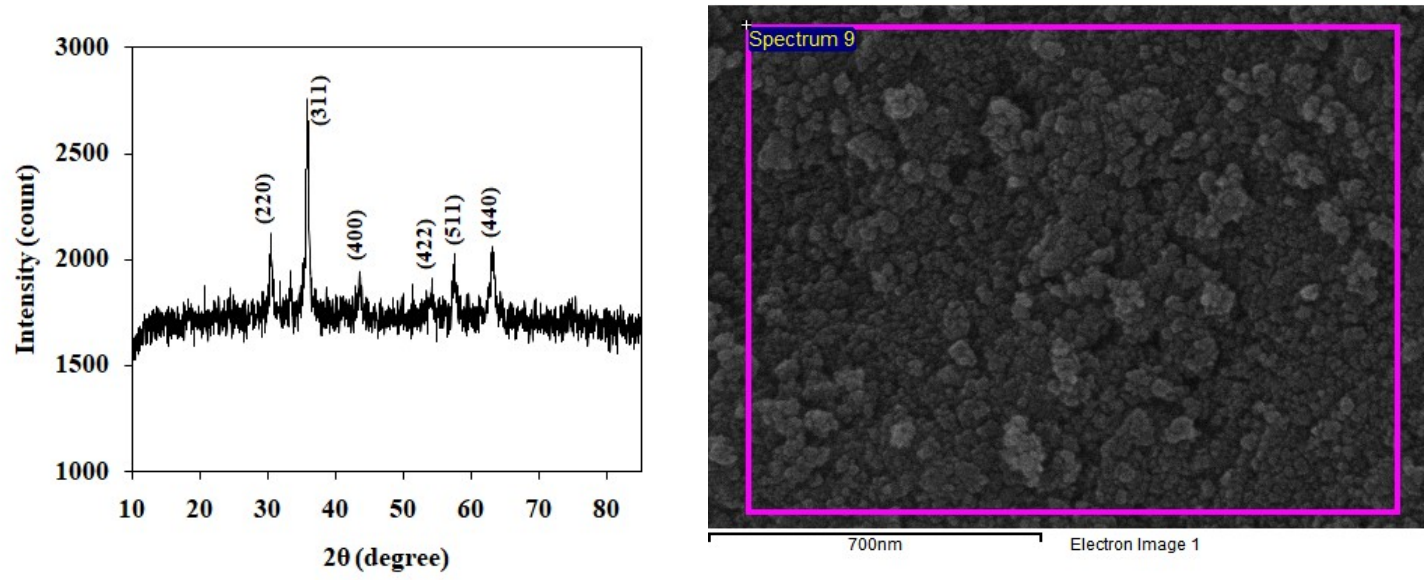

Fig.-1:(a) XRD and (b) SEM Image of m-MCNS Particles

The IR absorption peaks (Fig.-2a) at $3,780 \mathrm{~cm}^{-1}, 3,711 \mathrm{~cm}^{-1}$ and $3,645 \mathrm{~cm}^{-1}$ indicate the presence of intermolecular hydrogen-bonded N-H stretching. Also, the peaks at 2,883 $\mathrm{cm}^{-1}, 2,341.35 \mathrm{~cm}^{-1}, 1,597.60$ $\mathrm{cm}^{-1}, 640.07 \mathrm{~cm}^{-1}$, and $573.54 \mathrm{~cm}^{-1}$ correspond to the bending vibrations of $-\mathrm{CH}$, stretching vibrations in $\mathrm{CH}_{2}$, presence of $-\mathrm{NH}_{2}$ from glucosamine functional residue, and $\mathrm{Fe}-\mathrm{O}$ vibration on the surface of $\mathrm{Fe}_{3} \mathrm{O}_{4}$, respectively. ${ }^{13}$ VSM analysis examined the magnetic characteristic of the prepared nano-sorbent by oppressing it in the external magnetic field. The VSM hysteresis produced a magnetization value of $9.1917 \mathrm{emu} / \mathrm{g}^{14}$ (Fig.-2b). Results of the BET analysis of the m-MCNS particles showed a surface area of $28.29 \mathrm{~m}^{2} / \mathrm{g}$, pore volume of $0.098123 \mathrm{~cm}^{3} / \mathrm{g}$.
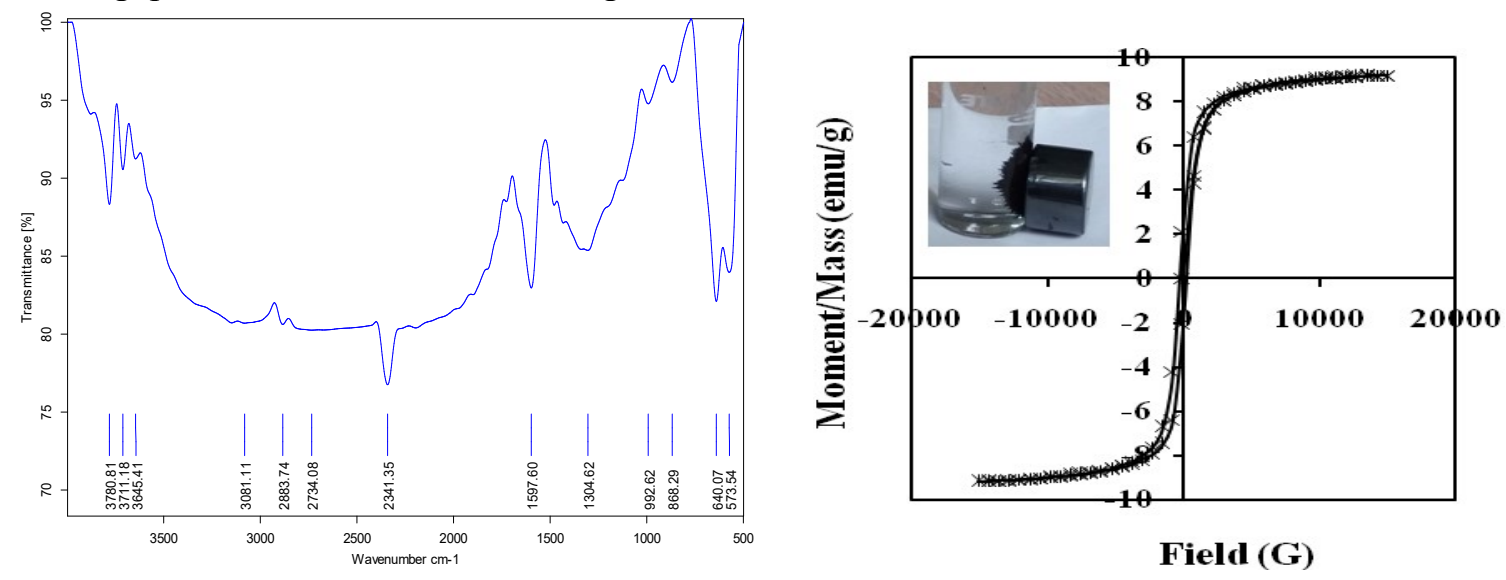

Fig.-2:(a) FTIR Spectrum (b) VSM Hysteresis Curve of m-MCNS Particles

\section{Influence of Operating Parameters}

Figure-3a, revealed that with the increment of m-MCNS dosage the \% $\mathrm{Cr}(\mathrm{VI})$ exclusion was increased and then decreased from 0.3 to $0.6 \mathrm{~g}$. It is because of the sufficient adsorption sites provided by the nanoadsorbent at higher dosages. From Fig.-3(b), it was noted higher removal was attained within $10 \mathrm{~min}$. and the gradual increase of the removal was observed from 10 to $50 \mathrm{~min}$ at the agitation rate of $200 \mathrm{rpm}$. It is because of the more surface area of contact and the mesoporous nanostructure provided by m-MCNS adsorbent. Fig.-3(c), shows that the removal increments with increasing the $\mathrm{pH}$ from 3 to 5.5. It is because of the acidic condition inducing the electrostatic interaction between the negative $\mathrm{Cr}_{2} \mathrm{O}_{7}^{2-}$ and $\mathrm{HCrO}_{4}{ }^{-}$ ions to the positively charged protonated $-\mathrm{NH}^{3+}$ groups present on the porous surfaces. ${ }^{15}$ At the lower $\mathrm{pH}$ values, the $\mathrm{Cr}(\mathrm{VI})$ removal was increased because of the presence of more amino groups in the adsorbent which enables and favors in conducting the desorption experiments ${ }^{16}$. Figure-3(d) shows the $\% \mathrm{Cr}$ (VI) 
RASĀYAN J. Chem.

Vol. 14 | No. 2 |1105-1109| April - June | 2021

removal was increased by escalating the concentration from 10 to $100 \mathrm{mg} / \mathrm{L}$, more. It was due to the higher functional groups present in the highly porous structure. It was observed that $98.7 \% \mathrm{Cr}(\mathrm{VI})$ exclusion was obtained at the optimal conditions such as $100 \mathrm{mg} / \mathrm{L}, 0.3 \mathrm{~g}$ of m-MCNS dosage, acidic $\mathrm{pH}$ value of 5.5, and at the contact time of $60 \mathrm{~min}$.

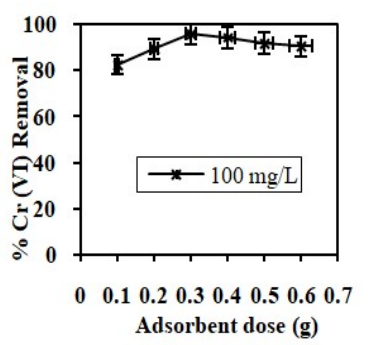

(a)

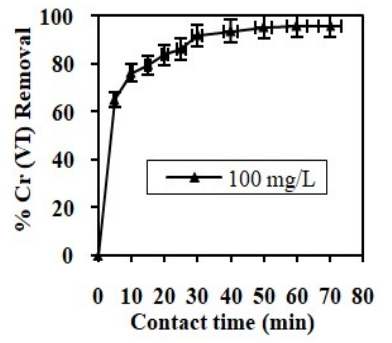

(b)

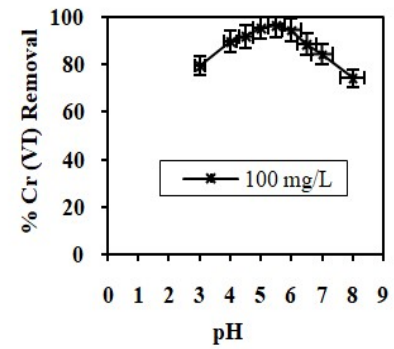

(c)

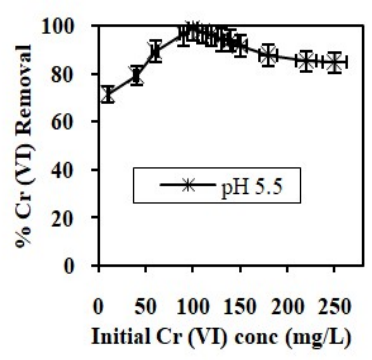

(d)

Fig.-3: Influence of Operating Parameters on Cr(VI) Exclusion (a) dosage (b) Time (c) pH (d) Initial Concentration

\section{Equilibrium Adsorption Studies and Kinetics}

The statistics of $\mathrm{Cr}(\mathrm{VI})$ removal by m-MCNS adsorbent fit the Langmuir adsorption isotherm model better (with $\mathrm{Q}_{\mathrm{m}}\left(\mathrm{mg} / \mathrm{g}\right.$ ) value of 98.04 , and $\mathrm{K}_{\mathrm{L}}(\mathrm{L} / \mathrm{mg}$ ) value of 0.214 ) which implies that it follows monolayer chemisorptions (Fig.-4a). The pseudo-second-order kinetics in aligned with the experimental values. The experimental adsorption limit of $24.33 \mathrm{mg} / \mathrm{g}$ is validated with the trial estimation of 25.73 $\mathrm{mg} / \mathrm{g}$ (Fig.-4b).

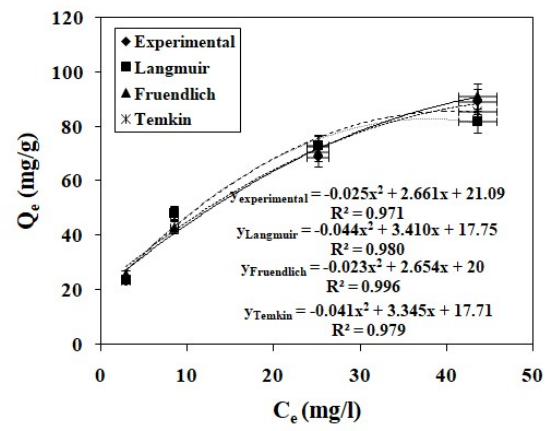

(a)

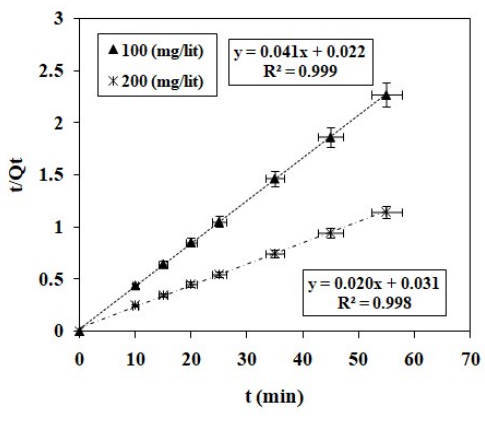

(b)

Fig.-4:(a) Comparison of Isotherms and (b) Kinetics for the Cr (VI) Removal by m-MCNS

\section{CONCLUSION}

The batch adsorption experiments were modelled, and the operating conditions were optimized. $98.7 \%$ of maximum $\mathrm{Cr}(\mathrm{VI})$ removal efficiency was obtained with the optimal conditions at an adsorbent dosage of $0.3 \mathrm{~g}$, contact time of $60 \mathrm{~min}$, initial Cr (VI) concentration of $100 \mathrm{mg} / \mathrm{L}$, and at a $\mathrm{pH}$ of 5.5. It has been concluded that the m-MCNS magnetic nano adsorbent is considered as a promising potential adsorbent for $\mathrm{Cr}(\mathrm{VI})$ removal from its aqueous mixture.

\section{REFERENCES}

1. T. Ravi, and Sathish Sundararaman., Journal of Environmental Chemical Engineering,8(2), 103877(2020), DOI:10.1016/j.jece.2020.103877

2. R. Rajkumar, S. Sathish, and P. Senthilkumar, Rasayan Journal of Chemistry, 11(1), 13(2018), DOI: 10.7324/RJC. 2018.1111893

3. Grzegorz Wojcik, Karolina Wieszczycka, Przemysław Aksamitowski, and Joanna Zembrzuska., Separation and Purification Technology, 238, 116410(2020), DOI:10.1016/j.seppur.2019.116410

4. A. Bashir, L.A. Malik, and S. Ahad, Environmental Chemistry Letter, 17, 729(2019), DOI: $10.1007 / \mathrm{s} 10311-018-00828-\mathrm{y}$

5. Junkai Gao, Yu Liu, Xuebin Li, Mouyuan Yang, Jinbao Wang and Yan Chen., Scientific Reports, 10, 7473(2020), DOI:10.1038/s41598-020-64191-1 
RASĀYAN J. Chem.

Vol. 14 | No. 2 |1105-1109| April - June | 2021

6. J. Aravind Kumar, D. Joshua Amarnath, S. Sathish, S. Anuradha Jabasingh, A. Saravanan, R.V. Hemavathy, K. Vijai Anand, and P.R. Yaashikaa, Journal of Molecular Liquids, 279, 77(2019), DOI: 10.1016/j.molliq.2019.01.121

7. U.B.L. Utami, B. Cahyono, and H. Susanto, Rasayan Journal of Chemistry, 13(4), 2106(2020), DOI: $10.31788 /$ RJC.2020.1345508

8. D. Das, and B.K. Nandi, Transactions of the Indian Institute of Metals, 73, 2053(2020), DOI: $10.1007 / \mathrm{s} 12666-020-01962-4$

9. Yage Xing, QinglianXu, Xingchen Li. Cunkun Chen, Li Ma, Shaohua Li, Zhenming Che, and Hongbin Lin, International Journal of Polymer Science, 2016, 1(2016), DOI:10.1155/2016/4851730

10. D. Prabu, P. Senthil Kumar, Kilaru Harsha Vardhan, S. Sathish, John Mathew, and Alan Raju, Desalination and Water Treatment, 203(1), 366(2020), DOI:10.5004/dwt.2020.26197

11. Dessalew Berihun, Journal of Material Science Engineering, 6, 331(2017), DOI:10.4172/21690022.1000331

12. Younes Dehmani, A. Awad Alrashdi, Hassane Lgaz, Taibi Lamhasni, Sadik Abouarnadasse, and IllMin Chung, Arabian Journal of Chemistry, 13(5), 5474(2020), DOI:10.1016/j.arabjc.2020.03.026

13. Fathy, Mahmoud, Selim, Hanaa, Shahawy, E.L. Abeer, Royal Society of Chemistry Advances, 10(39), 23417(2020), DOI:10.1039/D0RA02960B

14. D.W. Astuti, and N.H. Aprilita, Mudasir, Rasayan Journal of Chemistry, 13(2), 845(2020), DOI: $10.31788 /$ RJC.2020.1325537

15. C. Londolani, Maremeni, J. Sekomeng Modise, M. Fanyana Mtunzi, J. Michael Klink and E. Vusumzi Pakade, Bioinorganic Chemistry and Applications, 2018, 1(2018), DOI: $10.1155 / 2018 / 6171906$

16. Yibing Feng, Yi Du, Zhongtao Chen, Minxing Du, Kai Yang, XingjieLv, and Zhongfu Li, Journal of Coating Technology and Research, 15(5), 1145(2018), DOI:10.1007/s11998-018-0052-9

[RJC-6220/2020] 